\title{
Sexualidade, psiquismo e a educação sexual entre pais e filhos adolescentes
}

\author{
Maria José de Castro Nascimento* \\ Maria Lúcia Castilho Romera**
}

\section{RESUMO}

Trata-se de estudo sobre os aspectos psicossexuais que envolvem as dificuldades da Educação Sexual entre pais e filhos adolescentes. Com base nos pressupostos básicos psicanalíticos freudianos, e uso dos métodos clínico, indiciário e interpretativo, constituiu-se uma pesquisa qualitativa. Observações e entrevistas foram feitas com pail de adolescentes entre 13 e 18 anos de idade. Dados de campo e teóricos, revelaram que estrutura neurótica familiar além de mecanismos neuróticos da personalidade dos pais são os determinantes principais. Aspectos sócio culturais, também dificultam a Educação Sexual de filhos e filhas. Ponderou-se acerca dos mecanismos psicosociológicos eficazes que interditem a pulsão sexual nas famílias, e postulou-se a fantasia incestuosa inconsciente como núcleo mantenedor da trama familiar.

\footnotetext{
* Psicóloga, especialista em Orientação Sexual pela Universidade Federal de Uberlândia. ** Psicóloga. Doutora, Psicanalista pela SBPSP, Docente do Departamento de Psicologia e no Curso de Especialização em Orientação Sexual da Universidade Federal de Uberlândia.

Recebido em 10.09.99

Aprovado em 25.09.99
} 


\section{INTRODUÇÃO}

Dados de pesquisas apontam o fato de que pais e filhos adolescentes não se falam adequadamente sobre sexo e sexualidade. No cotidiano, junto aos pais, indiretamente, adolescentes pedem para falar sobre tais temas e paradoxalmente limitam espaços para conversas. A bibliografia a respeito de sexualidade, adolescência e Orientação Sexual tem aumentado nos últimos tempos, notadamente, devido à crescente preocupação com o aumento do número de gravidez precoce, e o aparecimento da Síndrome da Imuno Deficiência Adquirida (AIDS) e Doenças Sexualmente Transmissíves (DST). A alta incidência destes é atribuída a falta de Educação Sexual dos jovens.

Outro aspecto a ser considerado é aquele referente a importância dada a Orientação Sexual em escolas, além da polêmica questão sobre qual o melhor profissional para exercer o papel de Orientador Sexual. É, também, muito pesquisado, quando e onde o adolescente seria melhor orientado ou educado em termos de sexualidade, já que os pais primordialmente responsáveis por essa tarefa não o fazem.

Pelo fato de se estar tornando em consideração, neste trabalho, a relação pais e filhos, procurou-se especificar os termos Educação, Informação, Orientação, Ensino e Aconselhamento, ou seja, modalidades de serviços em sexualidade. Adotou-se o termo Educação, uma vez que este se refere a um processo contínuo na vida do indivíduo a portanto se aproxima mais do modelo de relação aqui enfocado.

Define-se então, Educação Sexual, como um procedimento em que o educando adquire condições maturativas e equilíbrio nas emoções dentro de seu contexto sócio cultural. O corpo que dá prazer físico, vai interagir com sua mente para que possa estar mais integrado enfrentando preconceitos, mitos e tabus, tornando-se assim, produtivo, crítico e criativo. $\mathrm{O}$ processo se inicia quando da gestação do indivíduo, indo do leito de nascimento ao de morte. Deve começar e estar sempre nos meios familiares e ser complementada e retroalimentada nos espaços sociais mais amplos. Enfim, deve preparar o indivíduo para o viver, fruto de amadurecimento físico e psicológico.

As pesquisas sobre Educação Sexual e adolescência são unânimes em apontar: as informações sobre sexo e sexualidade, são adquiridas em primeiro lugar com os colegas da mesma idade, depois recorrem às mães e em terceiro lugar, os adolescentes procuram professoras. Os adolescentes afirmam que os pais dão informações insuficientes, possuem reações negativas quando de cenas de sexo na $\mathrm{TV}$, e relatam que gostariam que os pais fossem mais abertos. Os dados revelam que os pais desconhecem a vida 
sexual ativa dos filhos adolescentes, especialmente das filhas. JESUS, TEMER e SILVA (1997), VITIELLO e CONCEIÇÃO (1988).

PFROMM NETO (1976:225) cita vários trabalhos das décadas de 40 a 60, onde dados semelhantes foram encontrados. Reservados os conflitos específicos que advém dos códigos sociais de época, um substrato psíquico se expressa nos conflitos entre pais e filhos adolescentes e permanece através das gerações.

Algumas hipóteses delimitaram essa investigação e algumas observações do cotidiano puderam ilustrar a proposta de estudo: fotos de bebês masculinos nus com o foco da câmara sobre os genitais, reações dos pais frente ao uso de anticoncepcionais pelas filhas solteiras e hostilidades à sogras. Na prática clínica, uma mãe relata um sonho onde fazia sexo com um filho adolescente, e pais falam de excitação sexual quando vêem a sensualidade das filhas adolescentes ou quando essas sentam-se em seus colos. Tais fatos requerem um olhar interpretante para serem apreendidos em outra ordem de significação e com isso auxiliar o Orientador Sexual no seu exercício profissional.

Questiona-se: por que os pais não conversam sobre sexo e sexualidade com os filhos adolescentes? Os pais não falam ou os adolescentes não absorvem as mensagens? O que acontece em termos de psicossexualidade que dificulta esse diálogo?

O ponto de partida da investigação teórica foram os pressupostos básicos da Teoria Psicanalítica freudiana os quais sejam: Complexo de Édipo, Fantasia, Fantasia Originária, Libido, Organização da Libido, Pulsão, Recalque, Sublimação e Objeto. Estes conceitos definem os aspectos ligados aos processos de nascer, sobreviver, morrer a preservação da espécie, e permite também, pensar que os impulsos instintivos mesmo sob a regência da cultura e dos mecanismos de defesa dos indivíduos, manifestam-se de formas mais ou menos inconscientes, independentes de raça, sexo ou parentesco, pois impõe-se como existência. Nos meios familiares aparece a fantasia incestuosa inconsciente, o que é constatado na prática clínica. Os impulsos necessitam de mecanismos adequados e processos de socialização para que o psiquismo humano elabore, produza e organize a cultura e a transcendência ao corpo.

\section{O novo velho conflito edipiano}

Alguns aspectos emocionais subjacentes à estruturação do psiquismo, são fundamentais para a compreensão das questões levantadas. Neste item, são abordados alguns aspectos psicossexuais dos adolescentes. 
Em “Romances Familiares", FREUD (1908) fala da perda internalizada dos pais, entre outros aspectos que são confirmados por diversos outros autores.

LEVISKY (1994) fala da dificuldade da aquisição de identidade nos dias atuais. Questões sociais e científicas interferem na forma de pensar, agir e na sexualidade do adolescente. Acredita que adolescer é uma situação ansiógena, pois há o reviver do conflito edipiano já com um corpo genitalizado e pais enquanto objetos reais. Há mudanças específicas a súbitas no corpo, e um código moral deve surgir nessa situação confusa. Além disso, o indivíduo deve integrar-se a uma sociedade mais ampla, e à heterossexualidade. Como conseqüências aparecem os comportamentos agressivos e antisociais. O fenômeno psicofisiológico da masturbação, toma um significado de treino para a genitalidade adulta, ocasião em que as atitudes dos pais tomam conotações diferenciadas, podendo levar os filhos à fortalecer uma simbiose mental com conseqüiente improdutividade intelectual e perda de oportunidade da fase para resolução de conflitos. Aspectos sociais, culturais e individuais de pais e filhos devem ser considerados nessas situações, pois os conflitos, que aqui são normais, podem passar a ser exacerbados.

\section{A nova velha adolescência}

Neste item, aborda-se os mecanismos psicossexuais das pessoas de meia idade e pais de adolescentes. Há a perda internalizada dos filhos, rivalidades e disputa a nível mais ou menos inconscientes de potência, beleza e intelectualidade. A finitude se apresenta, evolui-se para a morte e nega-se este fato. A personalidade dos pais deve estar bem estruturada, neste momento de redefinição existencial. A mulher não procria mais, o homem pode tornar-se promíscuo e há incentivos a infantilidade dos filhos. Aparece uma ansiedade quanto à Cena Primária de modo invertido e os pais podem tornar-se controladores e autoritários. Há dúvidas quanto à liberalidade, preconceitos e colocação de limites, levando os pais a discursos psicologizantes, suprimindo, reprimindo ou ignorando a sexualidade dos filhos. No aspecto sexual, agora, estão em igualdade, e surgem os jogos incestuosos aceitáveis, uma vez que pais e filhos não podem adquirir a atração sexual que é mútua, e os conflitos podem tornar características neuróticas ou até psicóticas. Esses dados são confirmados por LEVISKY (1995), e também por outros autores. 
Pais e filhos adolescentes estão passando por profundas mudanças orgânicas e psíquicas, as quais quando não conduzidas adequadamente podem levá-los até ao suicídio, segundo PROSEN e OUTROS (1981).

Como pode ser observado, enquanto os pais revivem os conflitos edipianos, os adolescentes os estão elaborando, sendo portanto uma fase de extrema dificuldade na vida destas pessoas na sociedade atual.

\section{Criança dentro do cesto... (para não dizer IN Cesto)}

A força da pulsão sexual na conduta humana é aqui abordada enquanto atuação, levando a vítima a ficar aprisionada no desenvolvimento de sua personalidade.

MARCELINE e OUTROS (1997) levantam aspectos etnopsiquiátricos e etnopsicanalíticos para a qualificação do ato incestuoso. Em todas as culturas a relação sexual entre pais e filhos é proibida, outros tipos são até culturalmente instituídas. Na nossa cultura ocidental ele é inaceitável, portanto seguramente patológico.

Como consequiências orgânicas nas vítimas são apontados: obesidade, anorexia, bulimia, náuseas, vômitos, mutismo, dores físicas difusas, incontinência fecal, amenorréia, lesões genitais e por tentativas de estrangulamento. E ainda enurese, encoprese, dores abdominais, crises de falta de ar, dermatoses e perturbações no sono. As conseqüências à nível psíquico são devastadoras a irreversíveis. Para a aquisição de identidade inexiste definições de papéis e imagens parentais. Há o despertar de prazeres narcísicos, se acontecem gratificações com dinheiro, e a vítima desenvolve comportamentos passivos uma vez que torna-se posse do agressor; levando-a ao suicídio se interromperem as agressões. São descritos ainda na literatura, terror, estresse, estado de choque, recuos, apatia e regressões comportamentais. Acontece uma destruição do corpo feminino como frigidez, ninfomania e desprezo pelos parceiros. Há ainda o medo mórbido de contrair gravidez, DST e AIDS, e situações constrangedoras quando de exames médico periciais em acompanhamentos jurídicos. A nível social, apresentam-se famílias desestruturadas, crianças negligenciadas, delinquências, prostituição, toxicomanias e ainda podendo as vítimas tornarem-se agressores sexuais quando crianças e também, após a adultez.

COHEN (1993) relaciona os sentimentos incestuosos de forma abrangente como fonte das produções das artes e da cultura através dos tempos. É identificado também, em diversas culturas e religiões e consi- 
derado básico na essência do ser humano. Por outro lado, aponta estudos em diversos países onde tipos, frequiência, e situações de incesto são pesquisados e como estes são tratados. A exemplo, calcula-se que atos incestuosos ocorrem em até $10 \%$ das familias. Em suas recentes pesquisas na cidade de São Paulo, detectou que 1/4 das denúncias de Abuso Sexual são casos de incestos e em $83 \%$ destes as vítimas coabitam com o agressor.

Acreditamos que o incesto intensificado mesmo à nível de fantasia inconsciente, levam a conseqüências indesejáveis na formação e estruturação da personalidade das vítimas.

\section{Família: vítima ou algoz?}

FREUD em "Totem e Tabu" (1913), fazendo uma abordagem antropológica, aponta que sociedades primitivas desenvolveram hábitos sociais no sentido de prevenir e punir severamente atos incestuosos. Prevenia-se o incesto principalmente entre irmãos a mãe/filho, através de costumes de evitação. A união acontecia de forma exogâmica e somente entre tribos representadas por animais Totêmicos diferentes. Pare organizer os comportamentos sociais, recorriam ao tabu, a lei não escrita mais antiga do mundo. A origem deste, segundo o autor, provem de idéias antitéticas onde sentimentos de horror aparecem, mas subjacentes identificam-se motivações inconscientes para a realização de atos proibidos. Surgia, estão, uma punição sobrenatural para evitar que o ato transgredido não fosse imitado. Neste texto, Freud definiu o que entendia como Homem Neurótico: um indivíduo com um funcionamento mental infantil ontogeneticamente semelhante aos povos primitivos, onde a lembrança de uma ação impele a execução do ato. Afirmou que nesses indivíduos, é necessário um grande esforço no sentido de suprimir ou reprimir os instintos, o que os leva a um empobrecimento psíquico.

Por outro lado, os núcleos familiares vem sofrendo modificações intensas nas últimas décadas. NICOLACI-DA-COSTA (1981) as entende e define através do processo de descontinuidade simbólica onde os códigos pessoais internalizados, notadamente, os da primeira infância entram em conflito com os novos códigos que vão surgindo na esfera social. 
Princípios semelhantes são levantados por outros autores. Pode-se identificar então, que crises individuais são responsabilidade da família, uma família que influencia o indivíduo, o qual interage e constrói o meio social, que define e redefine o individuo, a família e a sociedade continuamente. Sendo assim, conclui-se que crises são benéficas, e são a base pare o andamento da cultura.

\section{METODOLOGIA}

Privilegiou-se o método Clínico, que foi escolhido, em detrimento do Quantitativo que não evidencia as especificidades dos sujeitos. A experiência da autora com a psicanálise permitiu a escolha dos métodos Indiciário e Interpretativo, pois há a noção de conflito e cada palavra pode ter inúmeros sentidos. Os discursos foram re-significados em categorias discursivas, observando-se entonação de voz, pauses, interjeições, sutilezas e falar nas entrelinhas. Utilizou-se como técnicas a entrevista semi estruturada e a observação no local de moradia dos sujeitos.

Apenas pais de adolescentes foram entrevistados após a contextualização de cada sujeito quanto a idade, profissão, religião, atividades sócio culturais e observação do estilo de vida. $\mathrm{O}$ casal parental foi questionado quanto à sexualidade, com o objetivo de levantar mitos, preconceitos e tabus. Foi perguntado a pai e mãe se estavam satisfeitos com a forma como conversavam sobre sexo com os filhos, e o intuito era verificar se existia a como era a Educação Sexual. Verificou-se o nível da relação incestuosa inconsciente e a estrutura de personalidade dos pais ao se questionar que mudanças ocorreram no contato físico entre eles após o crescimento dos filhos. A finitude, o autoritarismo, reconhecimento e aceitação da vida sexual ativa dos filhos foi verificada com a questão sobre a reação dos pals frente a uma gravidez ou possível homossexualidade dos filhos. Por fim, verificou-se segundo a visão dos pais a melhor forma dos filhos receberem Educação Sexual e nessas últimas respostas foram evidenciadas as angústias dos pais frente às possibilidades ou não deles assumirem o papel de educadores sexuais.

Através de terceiros, os sujeitos foram contactados pare a entrevista em seus próprios casos. No total 8 pais foram entrevistados, ou seja, 4 mães e 2 casais. As entrevistas foram gravadas e técnicamente transcritas Pela própria pesquisadora. A média de idade dos pais foi de 42.5 anos de idade e do total de 18 filhos dos casais com variação de idade entre 10 e 20 anos, 
11 tinham entre 13 e 18 anos de idade, um critério que fora pré estabelecido. A média de idade dos filhos foi de 15.8 sendo 6 moças e 5 rapazes. Foi de 3 a média de filhos por casal. $\mathrm{O}$ grau de escolaridade dos pais variou de $2^{\circ}$ e $3^{\circ}$ graus a quatro religiões diferentes foram encontradas. Engenheiro, comerciantes, enfermeiras, professoras, microempresária e do lar foram as profissões. A composição familiar foi eminentemente nuclear, e os primeiros contatos foram feitos praticamente com as mães, e estas conscientemente ou não, excluíam os pais das entrevistas marcando horários em que somente elas estivessem em casa, embora fosse dito claramente que se estava entrevistando os pais de adolescentes. Apenas dois pais participaram da entrevista, e muito como expectadores, como se aquilo fosse "conversa de mulher".

Da pesquisa teórica e da parte prática foram surgindo os resultados e estes agrupados em quatro categorias a saber, e sobre as quais se falará a seguir.

\subsection{O reino de Édipo é aqui}

Nesta categoria foram levantados nas falas, aspectos psicossexuais expressos ora em atitudes de cunho sexual e afetivos, ora de hostilidades mútuas. Ora sedução, ora agressividades, inclusive entre irmãos. Fica evidenciado que algo acontece para que não haja atuação destes impulsos, os quais são identificados, também, frente a cenas de sexo na TV:

- ... é massaginha, beijo na boca... o do meio(18) fala tchau mãe, me beija, abraça, beija assim na boca mesmo...

- os meus filhos, os três $(20,15,13)$ eles andam pelados perto de mim (mãe) conversa comigo pelado, perto do pai, da minha filha (17)...

- de outros aceita bronca, agora eu (mãe) não... é tipo pingue pongue. Ontem na rua peguei um sapato e sentei nele...

- C. (15) é super manso, se ele me ver tirar o sutiã ele quer pegar nas minhas mamas, super manso, o único...

- eles não deixam a gente ver né?... eles morrem de vergonha... não deixam ver tomar banho... não deixa nada, se vai trocar de roupa fecha a porta.

- Ele (pai) mudava o canal ou tirava a M. (17) da sala... agora ela também tem vergonha, as vezes ela fica quieta no canto dela ou sai da sala. 
Fala de uma mãe que ilustra e resume essa categoria: ...do jeito que minha mãe criou nós só Deus! ...revista era escondida, ela ficava pageando... ela pegava e queimava... meu pas?! Uma vez minha mâe falou que um fulano estava em lua de mel... (enfatiza a admiração) haaah!!!... nossa mãe!!!.. meu pai deu um escândalo! Um esquete! Que aquilo não era coisa de falar perto da menina! Eu?!... perdi o jeito de sair do lugar, eu perdi a fala! Assustei de ver minha mãe falar aquela palavra!... achei assim aquilo um absurdo!... mas tão absurdo!... que eu não conformava!... eu queimei, eu peguei fogo assim na hora, custei a sair de perto dela, a dar um jeito de correr por ela ter falado aquela palavra!...

\subsection{Se Maomé não vai à montanha, tampouco montanha vai à Maomé}

Fazendo uma alusão às zonas montanhosas que surgem nos corpos púberes, e que a nível inconsciente, muito inquietam pais e filhos, nesta categoria, categoria, levantou-se nas falas, as dificuldades de aproximações mútuas. Os conflitos das pessoas de meia idade, também são evidenciados, suas atitudes frente ao envelhecimeto, a negação do crescimento dos filhos, o autoritarismo e curiosidade com a intimidade dos filhos também aparecem:

- Entra todo mundo assim num tipo de brincadeira (faz gesto de embolar com as mãos) eu nunca cheguei assim sentei, conversei, tento mostrar assim... experiência: vê fulana, vê ciclana...

- Eu cronometro hora de chegada, cronometro hora de saída... encho o saco...

- ...aí voce aproveita e dá a ensaboadinha do dia ...

- ...agora não ando encontrando não, mas já encontrei muitas (camisinhas) na carteira, sabe?

- ...de vez em quando dou uma geral no guarda roupa dela ...

- ...nós assistimos TV todos juntos, assim no tapete, eles, as namoradas, a gente mais junto... assim nas almofadas... tudo bonitinho! ...

- ...vida sexual ativa?... mais adulta... quando estivesse mais estabilizada... com a cabeça mais amadurecida... quando ela pudesse alugar uma casa, manter uma casa, pagar um aluguel...

- falo prá eles: a minha vida tá passando, a de vocês vem vindo, a minha vai e a de vocês tá vindo aí novinha, então vou viver agora, aproveitar agora que posso... 


\subsection{Educar ou não, EDUCAR eis a questão*}

Aqui, as falas denunciam o desejo dos pais de educar sexualmente os filhos, e as angústias de se sentirem impossibilitados de o fazerem. Aparecem os mecanismos de escamoteamento, os preconceitos, os mitos, a ênfase na procriação e na prevenção de doenças. Evidenciam-se posturas diferenciadas frente a vida sexual de moças e rapazes, atitudes contraditórias frente a valores julgados como modernos e a forte repressão sexual da moça negra:

- ...Icha!!... agora você me apertou...

- ...já vem do próprio sexo né? Do próprio nome... da parte sexual não é não? É do despertar, acordar.. assim pro sexo? (frente a questão $\mathrm{O}$ que é sexualidade)

- eu falo que sexo é muito bonito, muito gostoso, mas só dentro do casamento, porque tudo tem conseqüências... já pensou se engravidar uma moça?

- Falo sobre o uso de camisinha, evitar doença, doença... tanto uma gravidez indesejada, não só a AIDS que mata... muita doença venérea que é muito triste...

- Eu ia por eles assim numa atividade física para estravasar.. preencher o tempo deles no máximo... cansa a mente e o corpo... não precisa manter sexo.

- Lidar com o menino é mais fácil do que com a menina, seria aquele estilo assim: pimenta no olho do vizinho não arde tanto quanto no olho da gente. Talvez você tenha que educar o rapaz para assumir responsabilidades... mas você não estaria com o peso da barriga nas costas...

Fala de uma mãe negra:

- Tem que estudar, ser livre... viver... ser independente... agora se não for assim vão falar que você é puta... se quer começar a ga... (diria galinhar) fazer farra, se acha que tá na hora...

\subsection{Uma luz no fim do túnel...}

Nas falas dos pais fica evidente que sabem mas não sabem que sabem acerca de sexo e sexualidade. Intuitivamente, falam da necessidade

\footnotetext{
* Mudança de vírgula postulada por J. Lacan.
} 
de um amadurecimento psicológico, apontam soluções, se reconhecem despreparados, citam a escola como o melhor local para a Orientação Sexual. Preocupam-se com o profissional orientador, expressam o desejo de também se instruírem a demonstram esforços para mudanças de posturas através das gerações:

- ... é uma coisa de Deus, é o que deu origem a você, deu origem ao espírito, uma coisa que a gente é responsável por ele até a morte, é coisa séria...

- se acontecesse gravidez... is ver se eles queriam casar..

- eu sempre,fui extrovertida... pensei que quando eu tivesse meus filhos eu teria uma cabeça mais aberta com eles... acho que realmente eu não tenho...

- eu acho tão difícil a gente... saber lidar... se tivesse uma pessoa de fora... uma pessoa esclarecida... que fosse uma coisa sadia...

- se tivesse um serviço de orientação

- em grupos na comunidade, na igreja mesmo...

- até deixei a minha menina assistir filme pornô... ela ficava perguntando... não tinha jeito de explicar...

- eu compro assim revistas pra elas, quando tem uma coisa interessante...

- Educação Sexual na escola!... a pessoa só vai aprender depois que passa a convi ver... ensino é muito diferente disso...

- Eu acho que é a vida... não tem nada que ensina, é a vida, é o passar do tempo é um tudo... no dia a dia, no tranco vai aprendendo... é a vivência, a prática... é tudo...

\section{CONSIDERAÇÕES FINAIS}

O acesso à Informação Sexual, é pré determinado pela classe social do indivíduo. Embora essa seja confundida com Educação Sexual é um dos meios para pais e filhos estarem conversando sobre sexo e sexualidade.

À mãe é delegada a Educação Sexual no lar, função que assume automaticamente, excluindo o pai, e o faz sem perceber. Ao mesmo tempo, os pail expressam sentirem-se fora do processo, porém acomodados na situação. 
As informações sobre prevenção de doenças e contracepção são enfatizadas para os rapazes, os quais são mais livres dos efeitos da repressão devido a uma permissividade cultural quanto ao exercício da sexualidade. Mas os mecanismos de escamoteamento e negação da sexualidade de filhos e filhas adolescentes é regra geral, em contraposição à idéia de que há um incentivo para os moços e repressão para as moças.

Há por parte dos pais muitos preconceitos frente ao homossexualismo e gravidez de moça solteira. A condição racial é um fator muito forte para a repressão sexual feminina, há "transa" para moços e "galinhagem" e "putaria" para moças negras.

O que os filhos aprendem "é na rua". A escola é apontada unanimamente, como um terceiro que interdita a relação pais e filhos no tocante à Educação Sexual, ao mesmo tempo que os pais se denunciam despreparados para a função de educadores sexuais para seus filhos. Muito falaram mães e pais, de suas próprias vivências em termos de sexualidade durante a pesquisa, revelando-se também eles imaturos. Dizem de uma falta de espaço para que possam falar de si. Percebe-se que os pais lutam desesperadamente para darem aos filhos o alimento orgânico. Além disso se encontram em estado de inanição, famintos de alimento psíquico que precisam para nutrir os filhos. Para a transcendência biológica não há necessidade de Educação Sexual, e as famílias sofrem muito com suas características psicopatológicas.

Apontam soluções por eles encontradas que os tem ajudado nessa tarefa. As revistas, outrora rasgadas e queimadas pelos pais, hoje, estão estabelecidas como ponte para conversas, além dos pais encontrarem ali, respostas também às suas próprias questões. Soluções inovadoras foram encontradas, citaram filmes pornográficos como meio para efetivarem a Educação Sexual inclusive de moças. E se há algumas décadas pais e filhos se tratavam com meras formalidades, hoje permitem verem-se nús, e a alguns filhos é permitida a prática sexual com seus parceiros dentro das próprias casas.

Espaços como igrejas, associações de bairros, postos de saúde, também, são apontados como locais para acontecer a Educação Sexual dos filhos, além do escolar.

O nível de escolaridade dos pais, nesta amostra, pouco infuenciou como fator de melhor ou pior Educação Sexual para os filhos. As famílias mais abastadas facilitam informações sobre sexo e sexualidade, a estas determinam qualitativamente e Educação Sexual. Nestas famílias, os mecanismos repressores, autoritários e controladores com o tempo, vem 
tornando-se mais sofisticados e sutis; a exemplo, pais levam a buscam os filhos quando dos passeios e conhecem-lhes os e-mail. Acredita-se que isso é até necessário, para que se diferenciem papéis dentro das famílias.

No geral, a Educação Sexual entre pais e filhos são brincadeiras, falas indiretas, avisos, acontecimentos sem critérios de conteúdos, de como ou quando falar. Isto é considerado normal nessa fase de suas vidas e esses comportamentos não podem ser encarados simplesmente como conflitos nocivos; são apenas agravados e muito, devido ao relativo grau de dificuldade na repressão dos instintos em mentes infantilizadas, segundo a definição de Homem Neurótico de Freud, ou seja, quanto mais neurótica a família maiores as dificuldades. Pais mais amadurecidos psicossexualmente são melhores educadores sexuais para seus filhos. E filhos mais informados tem menos conflitos com os pais.

Se há uma estrutura familiar muito neurótica, ou até mesmo psicótica, onde os instintos são mais ou menos evidenciados, pode-se afirmar que há uma Fantasia Incestuosa Inconsciente permeando as relações familiares que podem intensificar as dificuldades da vida relacional de pais e filhos adolescentes.

A verdadeira Educação Sexual mostrou ser um exercício de humanização dos instintos, pois trata do que de mais humano há no ser que é a sua própria animalidade. Ela é muda, fala-se com gestos, tom de voz, maneira de se vestir, respeito à individualidade, "o ser e estar no mundo" dos pais é que tocam os filhos num processo continuo desde os seus nascimentos.

Educar sexualmente os filhos adolescentes é transmitir subjetividades, é ter maturidade psicossexual e conviver com as amplas e diferenciadas contradições humanas.

\section{REFERÊNCIAS BIBLIOGRÁFICAS}

1. COHEN, Cláudio. O incesto um desejo. São Paulo, Casa do Psicólogo Livraria e Editora Ltda., 1993.

2. FREUD, Sigmund. Obras completes. Imago Ed., vols. IX, XIII.

3. LABEL, Marceline e outros. Crianças vitimas de abuso sexual. São Paulo, Summus Editorial, 1997.

4. JESUS, Maria Cristina Pinto de, TEMER, Viviane Pena e SILVA, Márcia Almeida da, A educação sexual realizada na família e na escola: opinião de escolares adolescentes. Revista Brasileira de Sexualidade Humana, vol. 8, $\mathrm{n}^{\mathrm{o}} 1$, p. 133, 1997. 
5. LEVISKY, David Léo. Adolescência -Reflexões psicanalíticas. Porto Alegre, Ed. Artes Médicas Sul, 1995.

6. NICOLACI-DA-COSTA, Ana Maria. Mal estar na família: descontinuidade e conflito entre Sistemas Simbólicos. 1n: Cultura da Psicanálise. Ed. Saraiva. Org. FIGUEIRA, Sérvulo A, p. 147, 1981.

7. PFROMM NETO, Samuel. Psicologia da adolescência. $5^{a}$ ed., São Paulo, Biblioteca Pioneira, Instituto Nacional do Livro, 1976.

8. PROSEN, Harry, TOEWS, John e MARTIN, Robert. The life cycle of the family: parental midlife crisis and adolescent rebellion. Adolescent Psychiatry. 9:170-9, 1981.

9. VITIELLO, Nelson e CONCEIÇÃO, Isméri Seixas Cheque. Aceitação da vida sexual de filhas adolescentes solteiras: um estudo comparativo. Revista Brasileira de Ginecologia e Obstetrícia, vol. 10(7), 1988. 